\title{
Therapeutic Bronchoscopy Improves Spirometry, Quality of Life, and Survival in Central Airway Obstruction
}

\author{
Kamran Mahmood $^{\mathrm{a}}$ Momen M. Wahidi $^{\mathrm{a}}$ Samantha Thomas ${ }^{\mathrm{a}}$ \\ Angela Christine Argento $^{b}$ Neil A. Ninan ${ }^{c}$ Emily C. Smathers ${ }^{a}$ Scott L. Shofer ${ }^{a}$ \\ ${ }^{a}$ Division of Pulmonary, Allergy and Critical Care Medicine, Department of Medicine, Duke University Medical \\ Center, Durham, N.C., b Division of Pulmonary and Critical Care, Department of Medicine, Emory University, \\ Atlanta, Ga., and 'Division of Pulmonary Diseases, Critical Care and Environmental Medicine, Department of \\ Medicine, Tulane University Health Sciences Center, New Orleans, La., USA
}

\section{Key Words}

Central airway obstruction - Therapeutic bronchoscopy · Tracheobronchial stent · Quality of life · Transplantation, lung

\footnotetext{
Abstract

Background: Central airway obstruction (CAO) occurs in patients with primary or metastatic lung malignancy and nonmalignant pulmonary disorders and results in significant adverse effects on respiratory function and quality of life. $\mathbf{O b}$ jectives: The objective of this study was to assess the effect of therapeutic bronchoscopic interventions on spirometry, dyspnea, quality of life, and survival in patients with CAO. Methods: We prospectively studied patients who underwent therapeutic rigid bronchoscopy for CAO. Spirometry, San Diego Shortness of Breath questionnaire (SOBQ), and SF36 questionnaire responses were obtained before the procedure and at follow-up 6-8 weeks after the procedure. $\boldsymbol{R e}$ sults: Fifty-three patients (24 malignant and 29 nonmalignant $(A O)$, who underwent successful rigid bronchoscopic intervention, were enrolled. Airway stent placement and various debulking techniques including mechanical debridement and heat therapy were used. After bronchoscopy,
}

there was a significant increase in forced vital capacity $(2.2 \pm$ 0.91 I before, $2.7 \pm 0.80 \mathrm{I}$ after, $\mathrm{p}=0.009)$ and forced expiratory volume at $1 \mathrm{~s}(1.4 \pm 0.60 \mathrm{I}$ before, $1.8 \pm 0.67 \mathrm{I}$ after, $\mathrm{p}=$ 0.002 ). The SOBQ score improved from $55.8 \pm 30.1$ before the procedure to $37.9 \pm 27.25$ after the procedure $(p=0.002)$. In the SF-36, there was an improvement in almost all domains, with statistically significant improvement seen in several domains. Benefits were seen independent of the etiology of $\mathrm{CAO}$, site of intervention or stent placement. The patients with malignant $\mathrm{CAO}$, in whom airway patency could not be achieved, had a poor survival. Conclusions: Alleviation of CAO with therapeutic rigid bronchoscopy results in improvement in spirometry, shortness of breath, quality of life, and survival.

(c) 2015 S. Karger AG, Basel

\section{Introduction}

Central airway obstruction (CAO) is a cause of significant morbidity and an adverse prognostic indicator in patients with both malignant and nonmalignant pulmonary disorders. It has been shown to affect up to $20-30 \%$ of patients with primary or metastatic lung cancer [1-3]

\section{KARGER 125}

C 2015 S. Karger AG, Base

$0025-7931 / 15 / 0895-0404 \$ 39.50 / 0$

E-Mail karger@karger.com

www.karger.com/res
Kamran Mahmood, MD, MPH

Division of Pulmonary, Allergy and Critical Care Medicine Department of Medicine, Duke University Medical Center DUMC 102356, Durham, NC 27710 (USA)

E-Mail k.mahmood@duke.edu 
and may also arise as a complication of nonmalignant disorders such as post-intubation tracheal stenosis and postlung transplantation airway stenosis [4-6]. Optimal management strategies are not well defined, and the efficacy of current techniques is not established. Primary therapeutic modalities at the present time include radiation therapy and chemotherapy for malignant $\mathrm{CAO}$, while treatments for nonmalignant $\mathrm{CAO}$ usually include mechanical interventions, such as bronchoplasty, and surgical resection of the primary lesion.

Therapeutic bronchoscopy is increasingly performed to alleviate $\mathrm{CAO}$ in patients with malignant and nonmalignant diseases alike, with several small retrospective studies showing improved outcomes with this approach [2, 7-17]. However, there are few studies available that have systematically examined the impact of therapeutic bronchoscopy on pulmonary function, dyspnea, and quality of life (QOL) in patients with CAO [3, 18-20]. The goal of this study was to assess the physiologic and symptomatic impact of therapeutic rigid bronchoscopic interventions in patients with both malignant and nonmalignant disorders, specifically looking at the changes in spirometry and QOL measurements.

\section{Methods}

Patients with CAO presenting for therapeutic rigid bronchoscopy intervention between September 2010 and February 2013 were enrolled. The Duke University Institutional Review Board approved the protocol (IRB protocol No. Pro00001506). Inclusion criteria included clinically symptomatic patients with $50 \%$ or more narrowing of the trachea, mainstem, or lobar bronchi. Exclusion criteria included age $<18$ years, prior therapeutic intervention, pregnancy, or inability to obtain informed consent, perform spirometry, or complete the study questionnaires.

After informed consent was obtained, baseline spirometry was performed using a MicroLoop Spirometer (CareFusion Corp., San Diego, Calif., USA). Next, the University of California San Diego Shortness of Breath Questionnaire (SOBQ) and Short Form 36 Health Survey questionnaire (SF-36) were administered immediately before bronchoscopy. The spirometry and questionnaires were repeated 6-8 weeks after the procedure at the time of clinical follow-up.

\section{Shortness of Breath and Quality of Life Questionnaires}

To assess changes in shortness of breath, we used the SOBQ, a validated tool to assess dyspnea in patients with lung disease [21]. The patients are asked to rate their shortness of breath with activities of daily living. It has 24 items, and the score can range from 0 to 120 (better to worse). A minimal important difference of 8 (range 5-11) has been described in patients with pulmonary fibrosis [22].

QOL measurements were performed using the SF-36 questionnaire. SF-36 is a validated tool to assess QOL in a variety of clinical conditions including pulmonary disorders, malignancy, lung transplantation, and lung surgery $[23,24]$. Patient responses are summed to produce scores for 8 domains, as shown in tables 3 and 4 , and can range between 0 and 100 (worse to better). A minimal important difference of 3 (range 2-4) has been described in patients with pulmonary fibrosis [25].

\section{Therapeutic Bronchoscopy Interventions}

Therapeutic bronchoscopy included rigid bronchoscopy performed in the operating room. A rigid bronchoscope (Bryan Corporation, Woburn, Mass., USA) was inserted in the airway under general anesthesia. Patients were ventilated using an automated jet ventilator (Bear Jet-150). Rigid telescope, flexible bronchoscope, and other instruments were inserted through the primary lumen of the rigid bronchoscope. Airway dilation was performed with Controlled Radial Expansion (CRE) pulmonary balloon dilators (Boston Scientific, Natick, Mass., USA). Tumor debridement was performed with flexible or rigid forceps or by coring out with the rigid bronchoscope. Argon Plasma Coagulation (APC, ERBE USA, Inc., Marietta, Ga., USA) and rigid or flexible electrocautery (ERBE USA, Inc.) were used as preferred heat modalities for tumor ablation or hemostasis. Potassium-titinyl-phosphate laser (American Medical Systems, Inc., Minnetonka, Minn., USA) was also used in a limited number of cases.

The metal stents used were Ultraflex (Boston Scientific); hybrid stents were AERO (Merit Medical Endotek, South Jordan, Utah, USA); silicone stents were NOVATECH Dumon stents (Boston Medical Products, Inc., Westborough, Mass., USA) and Hood stents (E. Benson Hood Laboratories, Inc., Pembroke, Mass., USA).

In general, intraluminal malignant lesions were debrided after using heat modalities for tumor ablation and hemostasis. Extraluminal lesions causing compression of the airway were stented. Debridement along with stent placement was performed for mixed lesions. CAO in the lung transplant population was initially treated with repeated balloon dilation as described previously [5]. If the obstruction recurred, airway stenting was performed. Silicone and hybrid stents were used preferentially for the lung transplant-related central airway stenosis (CAS). However, uncovered metal stents were used if an airway takeoff was jailed or the other stents could not be deployed successfully because of anatomic configuration. About 1,000 flexible and 150 therapeutic rigid bronchoscopies per year are performed by the interventional pulmonary group at Duke University Medical Center. The average duration of therapeutic rigid bronchoscopy procedure is about $60 \mathrm{~min}$.

Routine treatment including chemotherapy and radiation was provided to the patients under the direction of their oncologists. Patients with nonmalignant $\mathrm{CAO}$ also underwent routine therapy for the underlying condition.

\section{Statistical Analysis}

Student's t test was used to compare continuous variables, and $\chi^{2}$ tests were used to compare categorical variables. Primary endpoints were survival, changes in forced expiratory volume at $1 \mathrm{~s}$ $\left(\mathrm{FEV}_{1}\right)$, and changes in shortness of breath and QOL scores. Spirometric changes of $200 \mathrm{ml}$ were considered clinically significant. Subgroup analyses included malignant versus nonmalignant patients, patients with a stent versus patients without a stent, and patients with bronchogenic cancer versus patients with nonbronchogenic, metastatic cancer. The association of change in $\mathrm{FEV}_{1}$ 
Table 1. Demographics of subjects

\begin{tabular}{|c|c|c|c|c|c|c|}
\hline Variables & $\begin{array}{l}\text { Total cohort } \\
(\mathrm{n}=53)\end{array}$ & Malignant group $(\mathrm{n}=24)$ & & \multicolumn{2}{|c|}{ Nonmalignant group $(\mathrm{n}=29)$} & $\mathrm{p}$ value \\
\hline Age, years & $57.9 \pm 13.1$ & $62.8 \pm 9.22$ & & \multicolumn{2}{|l|}{$53.8 \pm 14.58$} & 0.01 \\
\hline \multicolumn{7}{|l|}{ Gender } \\
\hline Male & $29(55 \%)$ & $13(54 \%)$ & \multicolumn{3}{|c|}{$16(55 \%)$} & 0.94 \\
\hline Female & $24(45 \%)$ & $11(46 \%)$ & & $13(45 \%)$ & & \\
\hline \multicolumn{7}{|l|}{ Race } \\
\hline Caucasian & $40(75.5 \%)$ & $16(67 \%)$ & \multicolumn{3}{|c|}{$24(83 \%)$} & \\
\hline Others & $4(7.5 \%)$ & $1(4 \%)$ & \multicolumn{3}{|c|}{$3(10 \%)$} & 0.08 \\
\hline BMI & $25.8 \pm 5.9$ & $26.7 \pm 5.51$ & & \multirow{2}{*}{\multicolumn{2}{|c|}{$\begin{array}{l}25.0 \pm 6.29 \\
7(241 \%)\end{array}$}} & 0.32 \\
\hline COPD & $16(30.1 \%)$ & $9(37.5 \%)$ & & & & 0.29 \\
\hline \multirow[t]{6}{*}{ Etiology of CAO } & & Squamous-cell lung cancer & $7(13 \%)$ & Lung transplant stenosis & $23(43 \%)$ & \\
\hline & & Adenocarcinoma, lung & $2(4 \%)$ & Tracheal stenosis & $4(8 \%)$ & \\
\hline & & Pheochromocytoma & $1(2 \%)$ & & & \\
\hline & & Melanoma & $1(2 \%)$ & & & \\
\hline & & Endometrial cancer & $1(2 \%)$ & & & \\
\hline & & Leiomyosarcoma & $1(2 \%)$ & & & \\
\hline
\end{tabular}

$\mathrm{p}$ value for the difference between the malignant and nonmalignant groups. NSCLC = Non-small-cell lung cancer.

Fig. 1. Patient enrollment.

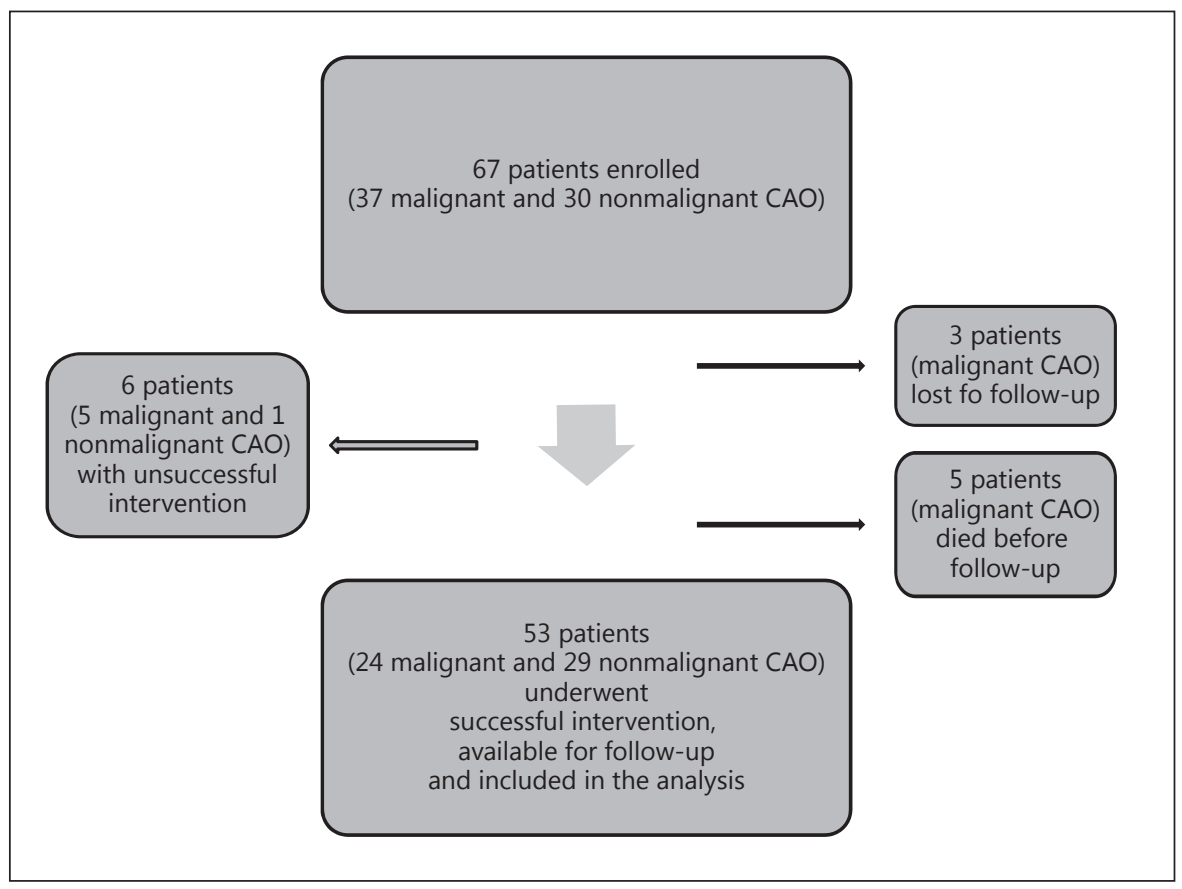


Table 2. Rigid bronchoscopy interventions

\begin{tabular}{lcccc}
\hline & $\begin{array}{l}\text { Total cohort } \\
(\mathrm{n}=53)\end{array}$ & $\begin{array}{l}\text { Malignant } \\
\text { group } \\
(\mathrm{n}=24)\end{array}$ & $\begin{array}{l}\text { Nonmalignant } \\
\text { group } \\
(\mathrm{n}=29)\end{array}$ & $\begin{array}{l}\mathrm{p} \\
\text { value }\end{array}$ \\
\hline Site of intervention & & & & 0.38 \\
Trachea & $8(12 \%)$ & $4(15 \%)$ & $4(10 \%)$ & \\
RMS & $15(23 \%)$ & $8(30 \%)$ & $7(17 \%)$ & \\
BI & $14(21 \%)$ & $4(15 \%)$ & $10(25 \%)$ & \\
RML & $3(4 \%)$ & $1(3 \%)$ & $2(5 \%)$ & \\
LMS & $12(18 \%)$ & $7(26 \%)$ & $5(12 \%)$ & \\
LUL & $7(10 \%)$ & $1(3 \%)$ & $6(15 \%)$ & \\
Lingula & $1(1.5 \%)$ & $1(3 \%)$ & 0 & \\
LLL & $5(7 \%)$ & 0 & $5(12 \%)$ & \\
\hline Type of intervention & & & & \\
Stent & $40 * 85$ & & \\
$\quad$ Metal & $19(47 \%)$ & $3(33 \%)$ & $16(52 \%)$ & \\
$\quad$ Silicone & $10(25 \%)$ & $3(33 \%)$ & $7(22 \%)$ & \\
$\quad$ Hybrid & $11(28 \%)$ & $3(33 \%)$ & $8(26 \%)$ & \\
Dilation & $29(55 \%)$ & $1(4 \%)$ & $28(97 \%)$ & $<0.001$ \\
Heat therapy & $32(60 \%)$ & & & $<0.001$ \\
$\quad$ Electrocautery & $19(36 \%)$ & $15(63 \%)$ & $4(14 \%)$ & $<0.001$ \\
$\quad$ APC & $9(17 \%)$ & $9(38 \%)$ & 0 & $<0.001$ \\
$\quad$ Laser & $7(13 \%)$ & $7(29 \%)$ & 0 & 0 \\
Debridement & $19(36 \%)$ & $19(79 \%)$ & 0 & \\
\hline
\end{tabular}

$\mathrm{p}$ value for the difference between the malignant and nonmalignant groups. ${ }^{*}$ Forty stents were placed in 34 patients: 9 stents were placed in 9 patients in the malignant group, and 31 stents were placed in 25 patients in the nonmalignant group. RMS = Right mainstem bronchus; $\mathrm{BI}=$ bronchus intermedius; $\mathrm{RML}=$ right middle lobe bronchus; $\mathrm{LMS}=$ left mainstem bronchus; $\mathrm{LUL}=$ left upper lobe bronchus; LLL = left lower lobe bronchus.

with change in SOBQ score and changes in SF-36 scores was tested using a linear regression model adjusted for known covariates including gender, race, age, BMI, and malignant status. The association of chronic obstructive pulmonary disease (COPD) diagnosis and site of intervention (nonlobar including trachea, mainstem bronchi, and bronchus intermedius vs. lobar bronchi) with change in $\mathrm{FEV}_{1}$, change in SOBQ, and changes in SF-36 scores was tested using an unadjusted linear regression model.

Survival was defined as time from procedure until time of death or last follow-up derived from the Duke University Medical center electronic medical record. For those still alive, survival was censored at April 1, 2013. Kaplan-Meier curves and log-rank tests were used to test for a difference in the overall survival of patients based on malignant status and type of malignancy.

A two-sided significance level of 0.05 was used for all statistical tests. No adjustments were made for multiple comparisons. All statistical analyses were conducted using SAS version 9.3 (SAS Institute, Cary, N.C., USA). Data are reported as mean \pm standard deviation unless noted otherwise.

\section{Results}

\section{Patient Enrollment}

Fifty-three patients were enrolled, underwent successful bronchoscopic intervention, and were available for follow-up (fig. 1). The intervention was considered successful if the airway patency of at least $50 \%$ was achieved. The airway patency could not be achieved in 5 patients with malignancy and 1 patient with nonmalignant disorder. Eight patients with malignancy did not undergo postprocedural testing ( 5 died due to underlying disease progression before they could be followed up, and 3 patients were lost to follow-up). The patients in whom the airway patency was achieved and who were available for follow-up were included in the final analysis. Twentyfour patients had malignant disorders and 29 had nonmalignant disorders. The mean time to follow-up was $40 \pm$ 23 days, when postprocedure spirometry and questionnaires were obtained. Patient demographics are shown in table 1.

\section{Interventions}

The site of interventions and various therapeutic procedures are shown in table 2 . Patients with malignant $\mathrm{CAO}$ were older, and underwent debridement and heat therapy more often compared to the patients with nonmalignant CAO (tables 1 and 2). Thirty-four patients had stent placement, with 5 patients requiring more than one stent. More patients in the nonmalignant CAO group underwent balloon dilation and stent placement. Twentyfive $(86 \%)$ patients in the nonmalignant group versus 9 (38\%) patients in the malignant group had stent placement. But, there was no significant difference in the type or site of stent placement between the groups. Between the two groups, there was no difference in improvement in spirometry, SOBQ, and SF-36, except for the Role Limitations - Physical Health domain, which favored improvement in patients with nonmalignant disorders (table 3). Radiologic studies showed atelectasis secondary to $\mathrm{CAO}$ in 8 patients with malignant CAO only and improved in 6 of these patients.

\section{Spirometry, Symptoms, and QOL Measurements}

$\mathrm{FEV}_{1}$ increased by $0.41(\mathrm{p}=0.002)$, and forced vital capacity $(\mathrm{FVC})$ increased by $0.5 \mathrm{l}(\mathrm{p}=0.009)$ after the procedure, as shown in table 4 and figures $2-4$. SOBQ score improved from 55.8 to 37.9 ( $\mathrm{p}=0.002)$. All the domains of SF-36 showed improvement, which was statistically significant for Physical Functioning, Role Limitations Physical Health, and Energy/Fatigue. The improvement 
Table 3. Comparison of outcomes between malignant and nonmalignant CAO

\begin{tabular}{lccc}
\hline Variables & $\begin{array}{l}\text { Malignant } \\
\text { group }\end{array}$ & $\begin{array}{l}\text { Nonmalignant } \\
\text { group }\end{array}$ & $\begin{array}{l}\text { p value for } \\
\text { difference } \\
\text { in mean }\end{array}$ \\
\hline Change in FEV 1,1 & $0.4 \pm 0.41$ & $0.4 \pm 0.56$ & 0.84 \\
Change in FVC, & $0.6 \pm 0.70$ & $0.3 \pm 0.63$ & 0.27 \\
Change in PEF, 1/min & $0.9 \pm 1.72$ & $0.7 \pm 1.19$ & 0.62 \\
Change in SOBQ & $-14.2 \pm 27.81$ & $-18.7 \pm 29.98$ & 0.57 \\
Change in Physical Functioning & $6.0 \pm 23.17$ & $15.6 \pm 31.25$ & 0.22 \\
Change in Role Limitations - Physical Health & $8.3 \pm 35.10$ & $31.9 \pm 46.24$ & 0.04 \\
Change in Role Limitations - Emotional Health & $4.2 \pm 53.22$ & $8.1 \pm 42.43$ & 0.77 \\
Change in Energy/Fatigue & $11.9 \pm 28.05$ & $8.6 \pm 26.98$ & 0.67 \\
Change in Emotional Well-Being & $3.8 \pm 23.10$ & $3.0 \pm 14.99$ & 0.88 \\
Change in Social Functioning & $6.8 \pm 32.76$ & $13.8 \pm 42.83$ & 0.51 \\
Change in Pain & $6.4 \pm 26.84$ & $-1.5 \pm 25.99$ & 0.29 \\
Change in General Health & $1.9 \pm 16.27$ & $5.3 \pm 21.85$ & 0.53 \\
\hline
\end{tabular}

$\mathrm{PEF}=$ Peak expiratory flow

Table 4. Rigid bronchoscopy outcomes

\begin{tabular}{lccc}
\hline Variables & Before intervention & After intervention & $\begin{array}{c}\text { p value for } \\
\text { difference } \\
\text { in mean }\end{array}$ \\
& & & 0.002 \\
FEV $_{1}, 1$ & & $1.4 \pm 0.60$ & 0.001 \\
FEV $_{1} \%$ & $47.8 \pm 19.43$ & $60.7 \pm 20.39$ & 0.009 \\
FVC, 1 & $2.2 \pm 0.91$ & $2.7 \pm 0.80$ & 0.006 \\
FVC\% & $57.8 \pm 21.08$ & $68.8 \pm 17.53$ & 0.05 \\
PEF, 1/min & $3.6 \pm 1.92$ & $4.4 \pm 1.92$ & 0.03 \\
PEF\% & $48.7 \pm 22.44$ & $59.3 \pm 22.91$ & 0.002 \\
SOBQ & $55.8 \pm 30.1$ & $37.9 \pm 27.25$ & 0.04 \\
Physical Functioning & $37.5 \pm 28.40$ & $49.4 \pm 29.90$ & $<0.001$ \\
Role Limitations - Physical Health & $7.5 \pm 23.81$ & $29.3 \pm 39.83$ & 0.34 \\
Role Limitations - Emotional Health & $67.9 \pm 44.80$ & $75.7 \pm 37.41$ & 0.02 \\
Energy/Fatigue & $40.7 \pm 26.93$ & $51.5 \pm 21.29$ & 0.29 \\
Emotional Well-Being & $73.8 \pm 21.52$ & $77.7 \pm 15.31$ & 0.07 \\
Social Functioning & $54.2 \pm 36.44$ & $65.6 \pm 26.65$ & 0.73 \\
Pain & $74.6 \pm 29.19$ & $76.4 \pm 24.90$ & 0.33 \\
General Health & $47.3 \pm 21.20$ & $51.5 \pm 22.87$ & \\
\hline
\end{tabular}

PEF $=$ Peak expiratory flow

in the other domains reached the clinically important threshold, except for Pain.

The site of intervention was not associated with improvement in lung function, SOBQ, or SF-36 domains, except for improvement in the Energy/Fatigue domain of SF-36 (table 5). Lobar intervention was done primarily to prevent postobstructive pneumonia or improve lung function in single lung transplant patients. In multivari- ate regression analysis, the improvement in $\mathrm{FEV}_{1}$ of $\geq 200$ $\mathrm{ml}$ was not significantly associated with the malignancy, site of intervention, or stent placement. Improvement in $\mathrm{FEV}_{1}$ was not associated with COPD diagnosis in patients with malignant $\mathrm{CAO}(\mathrm{p}=0.18)$.

Improvement in $\mathrm{FEV}_{1}$ after bronchoscopic intervention correlated significantly with improvement in SOBQ scores $(p<0.0001)$ in a multivariate linear regression 


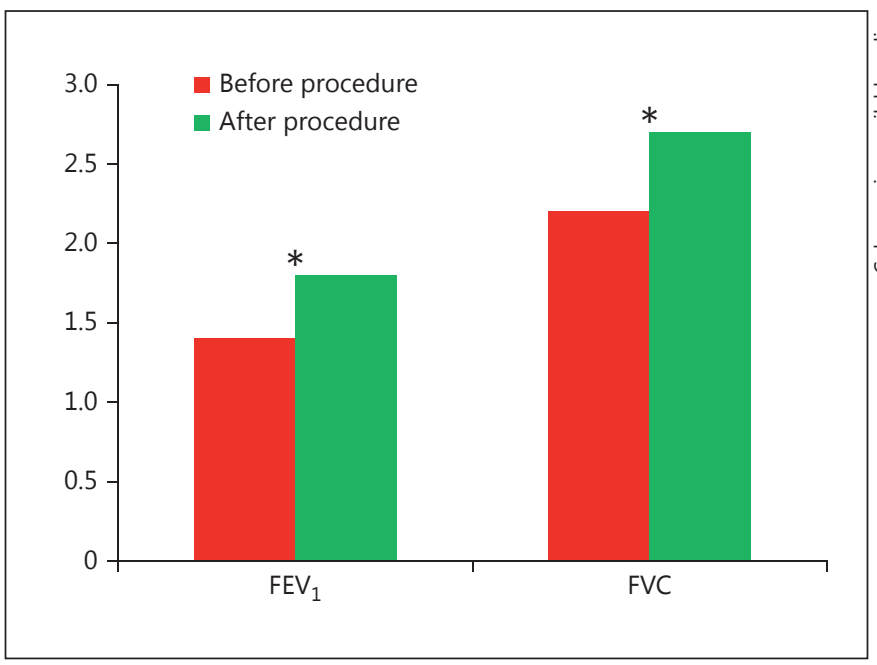

Fig. 2. Change in spirometry after bronchoscopic intervention. * Statistically significant change.

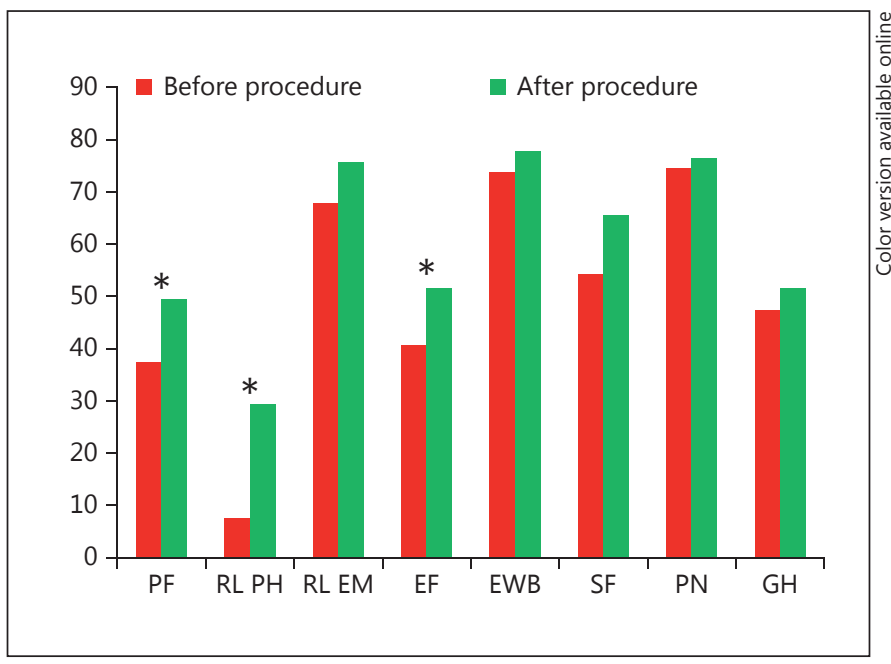

Fig. 4. Change in SF-36 domains after bronchoscopic intervention. $\mathrm{PF}=$ Physical Functioning; RL PH = Role Limitations - Physical Health; RL EM = Role Limitations - Emotional Health; EF = Energy/Fatigue; EWB = Emotional Well-Being; SF = Social Functioning; PN = Pain; GH = General Health. ${ }^{*}$ Statistically significant change.

analysis after controlling for age, gender, race, BMI, and malignancy status. However, in the QOL measurements, improvement in $\mathrm{FEV}_{1}$ correlated only with improvement in scores of the General Health and Physical Functioning domains ( $\mathrm{p}=0.007$ and $<0.0001$, respectively).

Bronchoscopy in Central Airway Obstruction

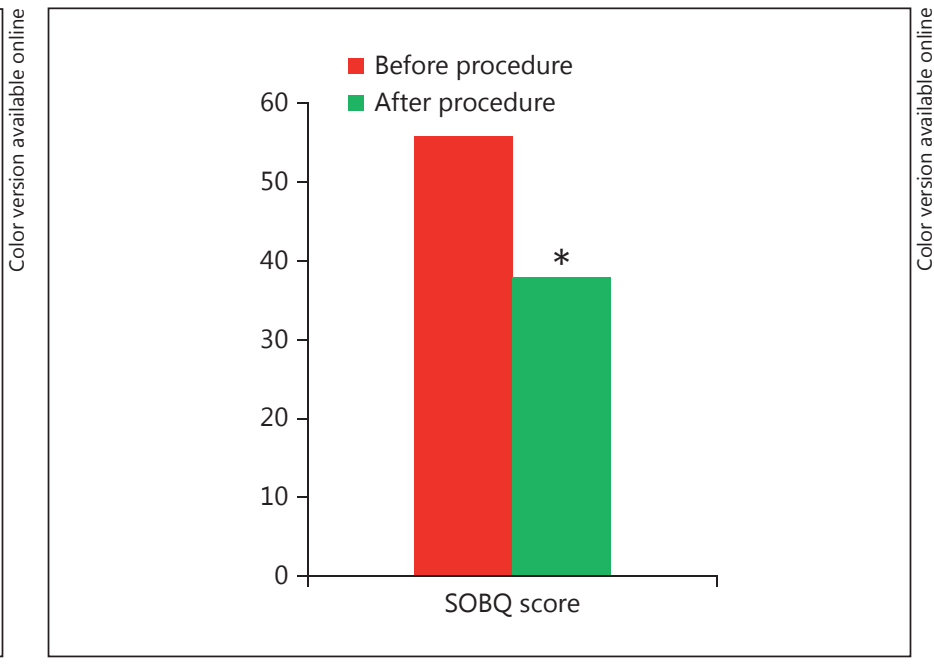

Fig. 3. Change in SOBQ after bronchoscopic intervention. * Statistically significant change.

\section{Survival}

The median survival was better in the nonmalignant group compared to the malignant group (480 vs. 212 days, $\mathrm{p}<0.0001$; fig. 5). The bronchoscopic intervention was unsuccessful in 6 patients, of whom 5 had malignant CAO. The median survival in patients with malignant CAO who underwent successful intervention was better compared to patients with unsuccessful intervention (229 vs. 115 days; fig. 6). The median survival in patients with $\mathrm{CAO}$ associated with bronchogenic carcinoma was worse but not statistically different from metastatic nonbronchogenic cancer ( 242 vs. 281 days, $p=0.80$; fig. 7 ). Complications of rigid bronchoscopy and stents are outlined in tables 6 and 7, respectively.

\section{Discussion}

This study shows that therapeutic bronchoscopy improves spirometry and QOL and relieves dyspnea in patients with CAO. This improvement is observed regardless of the underlying cause of airway obstruction, with changes of similar magnitude between patients with malignant or nonmalignant disease. These findings are unique in that we have prospectively collected a contemporaneous population of patients with and without malignancy and have shown similar improvements in physiologic and symptomatic parameters, supporting the concept that these improvements may be related solely to the 


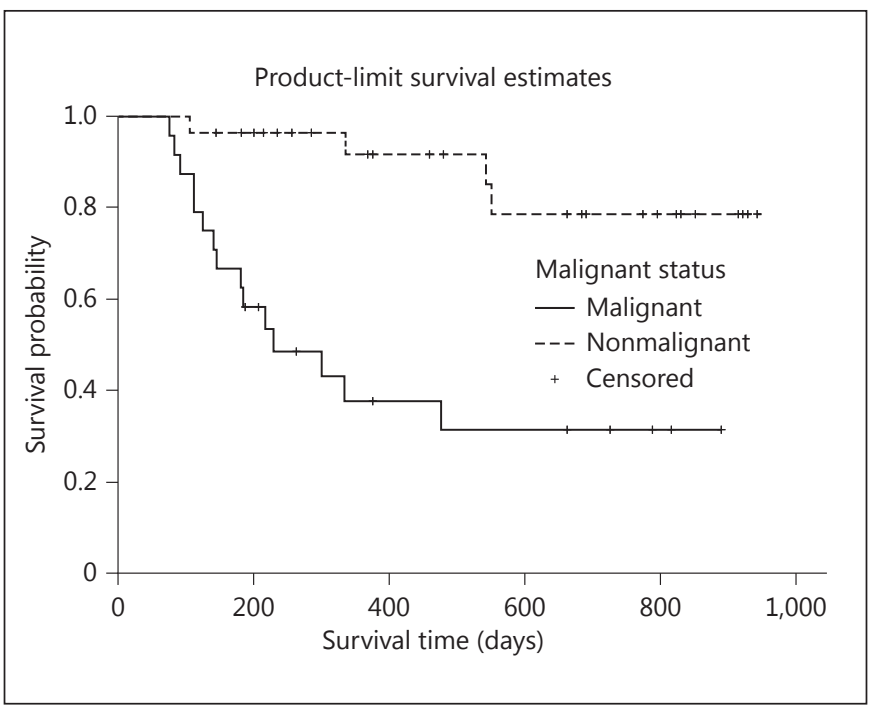

Fig. 5. Survival curve comparing patients with malignant and nonmalignant CAO.

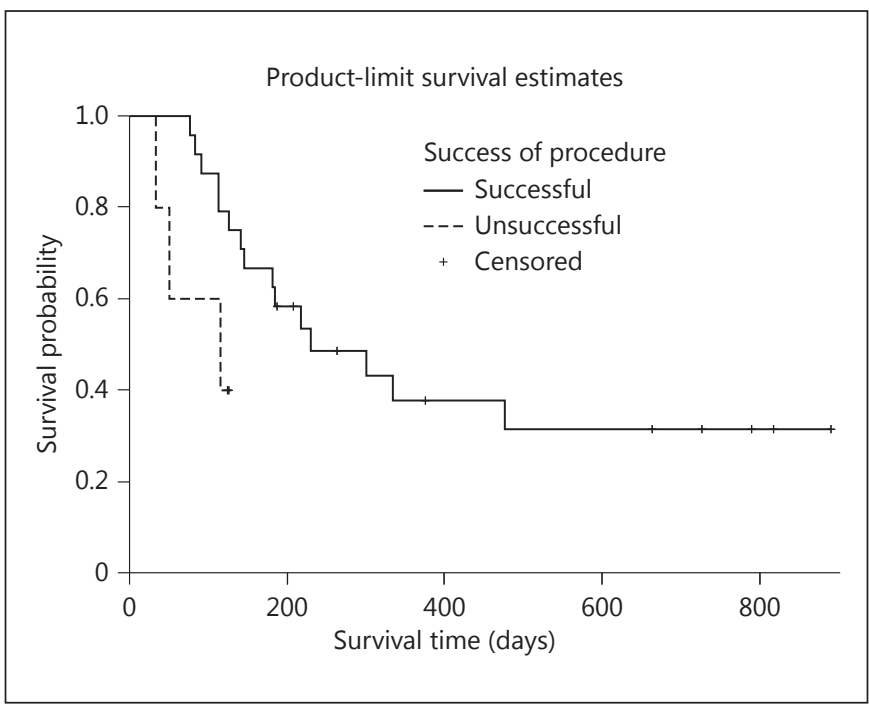

Fig. 6. Survival curve of patients with malignant CAO who had successful versus unsuccessful procedure.

Table 5. Comparison of outcomes between lobar and nonlobar CAO

\begin{tabular}{lccc}
\hline Variables & $\begin{array}{c}\text { Lobar inter- } \\
\text { vention group }\end{array}$ & $\begin{array}{c}\text { Nonlobar inter- } \\
\text { vention group }\end{array}$ & $\begin{array}{l}\text { p value for } \\
\text { difference } \\
\text { in mean }\end{array}$ \\
\hline Change in FEV 1,1 & $0.3 \pm 0.30$ & $0.4 \pm 0.52$ & 0.35 \\
Change in SOBQ & $-15.9 \pm 27.02$ & $-16.8 \pm 29.54$ & 0.93 \\
Change in Physical Functioning & $8.2 \pm 34.26$ & $11.9 \pm 26.83$ & 0.71 \\
Change in Role Limitations - Physical Health & $35.0 \pm 39.44$ & $18.0 \pm 43.41$ & 0.26 \\
Change in Role Limitations - Emotional Health & $0.0 \pm 49.69$ & $7.8 \pm 47.07$ & 0.64 \\
Change in Energy/Fatigue & $-5.0 \pm 27.69$ & $13.6 \pm 26.23$ & 0.05 \\
Change in Emotional Well-Being & $-2.4 \pm 21.18$ & $4.7 \pm 18.34$ & 0.29 \\
Change in Social Functioning & $10.0 \pm 42.41$ & $10.8 \pm 37.95$ & 0.96 \\
Change in Pain & $3.0 \pm 20.44$ & $1.9 \pm 27.83$ & 0.90 \\
Change in General Health & $7.0 \pm 26.69$ & $3.0 \pm 17.64$ & 0.56 \\
\hline
\end{tabular}

Nonlobar sites included trachea, mainstem bronchi and bronchus intermedius.

intervention performed irrespective of any adjunctive therapies. The higher increase in the Role Limitations Physical Health score in nonmalignant CAO patients could be because they generally lead a more active life, for example, participate in pulmonary rehabilitation, etc., and may be able to better judge the improvement in role limitation.

Patients with nonmalignant $\mathrm{CAO}$ had a better survival compared to those with malignant $\mathrm{CAO}$, which was expected based on the underlying disease prognosis. The survival was also better in patients who underwent successful interventions compared to those with unsuccessful interventions, primarily in malignant CAO. Although it could be related to the worse burden of disease, improved lung function and prevention of postobstructive complications may play a role. It was interesting to note that there was no significant difference in survival of patients with $\mathrm{CAO}$ associated with bronchogenic cancer versus nonbronchogenic cancer. This probably points to worse prognosis in the latter group. 


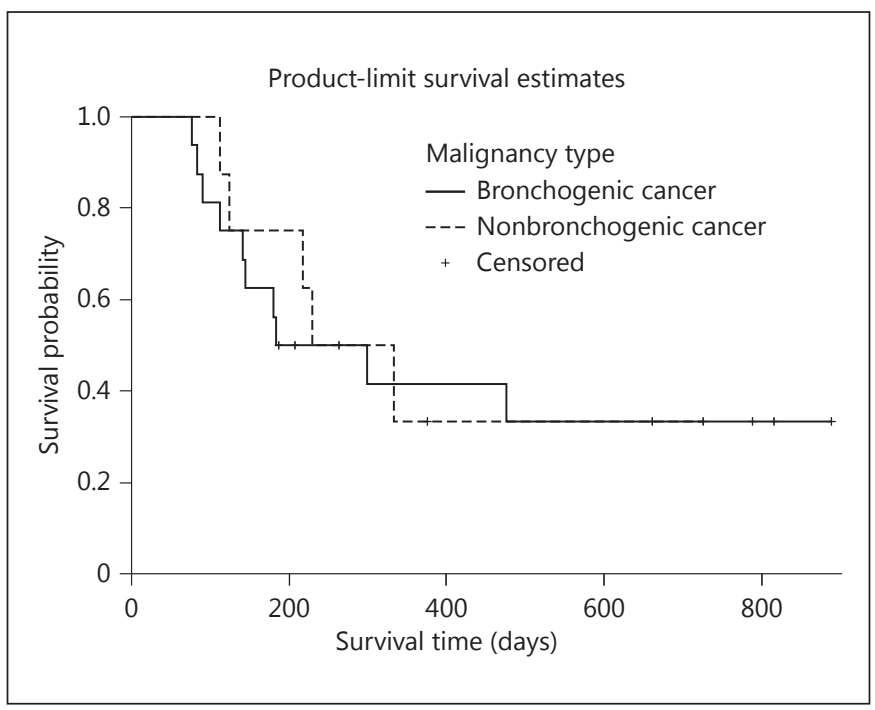

Fig. 7. Survival curve of patients with $\mathrm{CAO}$ and bronchogenic carcinoma versus nonbronchogenic carcinoma.

All the interventions were performed with rigid bronchoscopy. The rigid bronchoscope provides a secure conduit for airway maintenance and ventilation $[1,26]$. The large size of the rigid instruments like rigid forceps, rigid electrocautery, and dilation of stenosis or 'coring out' of tumor with the rigid bronchoscope make the procedure more efficient [1]. Besides, silicone stents can be deployed with the rigid instruments only [27].

We found strong correlations between changes in $\mathrm{FEV}_{1}$ and symptoms and QOL as assessed by surveys, which is in contrast to many studies in patients with COPD [28]. Recently, Handa et al. [29] reported the use of impulse oscillometry as an effort-independent modality that showed improvement with therapeutic bronchoscopy. In contrast to the present study, they did not find a correlation between improved spirometry and dyspnea score; the latter was measured by the Medical Research Council dyspnea scale. Our study did not show an association between spirometric improvement and interventions at a particular anatomic site, suggesting that even interventions in the distal airways may result in physiologic and symptomatic benefits.

Several studies have previously reported improvement in dyspnea and QOL assessments following bronchoscopic intervention for malignant CAO. Oviatt et al. [3] reported on 37 patients with malignant $\mathrm{CAO}$ who underwent rigid bronchoscopic therapeutic interventions in addition to standard oncologic treatment. There was improvement of about $100 \mathrm{~m}$ on the 6 -min walk test. QOL
Table 6. Complications of the rigid bronchoscopy

\begin{tabular}{ll}
\hline Complications & Interventions required \\
\hline Left mainstem tear & $\begin{array}{l}\text { Hybrid stent placement, removed after } \\
3 \text { weeks }\end{array}$ \\
Transient hypoxemia & $\begin{array}{l}\text { Corrected with changes in jet ventilator } \\
\text { settings } \\
\text { Small-bore chest tube placement }\end{array}$ \\
\hline
\end{tabular}

Table 7. Long-term complications of the stents

\begin{tabular}{llll}
\hline Complications & Stent type & $\begin{array}{l}\text { Stents with } \\
\text { complications, } \\
\text { n }\end{array}$ & $\begin{array}{l}\text { Mean interval } \\
\text { between } \\
\text { placement and } \\
\text { complication, } \\
\text { months }\end{array}$ \\
\hline $\begin{array}{llll}\text { Stenosis with } \\
\text { granulation tissue }\end{array}$ & $\begin{array}{l}\text { Metal } \\
\text { Silicone }\end{array}$ & 3 & 5.3 \\
& Hybrid & 2 & 5 \\
Migration & Silicone & 1 & 3.5 \\
\hline Hybrid & 4 & 2 \\
$\begin{array}{l}\text { Obstruction with } \\
\text { secretions } \\
\text { requiring removal }\end{array}$ & Hybrid & 1 & 4.8 \\
\hline
\end{tabular}

and dyspnea improved as assessed by the European Organization for Research and Treatment of Cancer Quality of Life (EORTC QLQ-C30) and Lung Cancer (LC13) modules. In a recent study from the AQuIRE (ACCP Quality Improvement Registry, Evaluation and Education) database, in which our institution participated, Ost et al. [30] reported outcomes of therapeutic bronchoscopy. Spirometry data were not reported, while dyspnea using the Borg score and QOL using the SF-6D were measured in only $20 \%$ of 947 patients. Less than half of these patients showed improvement in these outcomes. Neumann et al. [18] reported improved outcomes with flexible therapeutic bronchoscopy in their patients with malignant CAO. In another study, Amjadi et al. [19] demonstrated improvement in dyspnea without benefit in QOL in malignant CAO. This study differs from our cohort as spirometry was not evaluated and patients did not receive concurrent chemotherapy or radiation. Seventy percent of our patients with malignant $\mathrm{CAO}(17 / 24)$ received chemotherapy and radiation between intervention and follow-up. The study cannot rule out the benefits of these 
therapies. However, improvements in spirometric values and QOL were similar in both malignant and nonmalignant groups. The patients with nonmalignant CAO did not undergo additional therapy other than bronchoscopic intervention, suggesting that the intervention was the primary means of improved function in both groups. Nevertheless, therapeutic bronchoscopy should be considered as part of the multidisciplinary management of airways malignancy along with conventional chemoradiation.

We defined central airways as the airways which are usually traversable with a flexible bronchoscope of 6.3 $\mathrm{mm}$ outer diameter [5]. These airways include trachea, mainstem bronchi, bronchus intermedius, and lobar bronchi. In our study, the therapeutic intervention was considered successful if at least $50 \%$ patency of the airway lumen could be achieved. This criterion has been used in other studies [30, 31], and a success rate of $85-98 \%$ is reported with bronchoscopic interventions for malignant CAO. In our series, the intervention was unsuccessful in $6 / 59$ patients, mostly in patients with malignancies, and the success rate was $89.9 \%$. Patients who underwent successful interventions had a better survival compared to the patients in whom airway patency could not be achieved.

Our study also showed improvement in physiologic and QOL measures in patients with nonmalignant CAO. Most of these patients had lung transplant-related CAS. CAS in lung transplant patients is thought to be secondary to airway ischemia, infections, or acute rejection [5, 6]. It has been associated with decreased lung function and worse survival $[5,6,32]$. It is also associated with prolonged mechanical ventilation, hospital and ICU length of stay, increased cost, and poor QOL [33, 34].

Several retrospective studies have demonstrated improvement in spirometry with various types of airway stents in lung transplant-related CAS. Fernandez-Bussy et al. [13] reported their retrospective experience of 223 patients with lung transplantation. Twenty percent of patients developed airway complications, mostly airway stenosis. Balloon dilation followed by placement of metal or hybrid stents was required in $67 \%$ patients. $\mathrm{FEV}_{1}$ and FVC improved following the intervention. Similar findings have been reported by others, including in patients with vasculitis- and tuberculosis-related airway stenosis $[14-16,35]$.

Our study is unique as we prospectively evaluated the spirometry, dyspnea, and QOL in our cohort of nonmalignant CAO patients, who primarily consisted of lung transplantation patients. We demonstrated that the in- crease in pulmonary function after bronchoscopic interventions led to decreased dyspnea and improvement in the QOL.

The strength of our study is prospective, systematic evaluation of the impact of therapeutic rigid bronchoscopic interventions in patients with CAO. We demonstrate the safety of multimodality interventions, intraoperatively and at a short-term follow-up of 6 weeks. This study is limited by the lack of a control group which did not undergo rigid bronchoscopic intervention. However, given the severity of symptoms in these patients, we and other experts believe it would be unethical to withhold bronchoscopic therapy in patients with $\mathrm{CAO}$ [1]. We cannot rule out a placebo effect in the absence of control, but it seems to be less likely in view of significant spirometric and radiologic improvement. Another limitation of the study is the fact that some patients with malignant CAO died because of their disease progression before they could be followed up. Hence, the improvement in malignant CAO patients is demonstrated in only the patients available for follow-up. Unfortunately, this patient population has a poor prognosis, and inability of complete follow-up was seen in other studies as well [3].

In conclusion, therapeutic rigid bronchoscopic interventions improve spirometry, symptoms and QOL in patients with malignant and nonmalignant $\mathrm{CAO}$. These interventions should be part of standard management strategies for selected patients with CAO.

\section{Acknowledgements}

We acknowledge the developers of the SF-36 and SOBQ questionnaires. These questionnaires were used without any modifications. The SF-36 questionnaire was developed at RAND Corporation, Santa Monica, Calif., USA, as part of the Medical Outcomes Study. The SOBQ questionnaire was developed by UCSD, La Jolla, Calif., USA.

\section{Financial Disclosure and Conflicts of Interest}

The authors have nothing to disclose.

References

$$
\begin{aligned}
& \text { Ernst A, Feller-Kopman D, Becker HD, Meh- } \\
& \text { ta AC: Central airway obstruction. Am J } \\
& \text { Respir Crit Care Med 2004;169:1278-1297. } \\
& 2 \text { Venuta F, Rendina EA, De Giacomo T, et al: } \\
& \text { Nd:YAG laser resection of lung cancer invad- } \\
& \text { ing the airway as a bridge to surgery and pal- } \\
& \text { liative treatment. Ann Thorac Surg 2002;74: } \\
& \text { 995-998. }
\end{aligned}
$$

Mahmood/Wahidi/Thomas/Argento/ Ninan/Smathers/Shofer 
-3 Oviatt PL, Stather DR, Michaud G, Maceachern P, Tremblay A: Exercise capacity, lung function, and quality of life after interventional bronchoscopy. J Thorac Oncol 2011;6: $38-42$.

4 Thistlethwaite PA, Yung G, Kemp A, et al: Airway stenoses after lung transplantation: incidence, management, and outcome. J Thorac Cardiovasc Surg 2008;136:1569-1575.

5 Shofer SL, Wahidi MM, Davis WA, et al: Significance of and risk factors for the development of central airway stenosis after lung transplantation. Am J Transplant 2013;13: 383-389.

6 Castleberry AW, Worni M, Kuchibhatla M, et al: A comparative analysis of bronchial stricture after lung transplantation in recipients with and without early acute rejection. Ann Thorac Surg 2013;96:1008-1017.

7 Cavaliere S, Venuta F, Foccoli P, Toninelli C, La Face B: Endoscopic treatment of malignant airway obstructions in 2,008 patients. Chest 1996;110:1536-1542.

8 Bolliger CT, Probst R, Tschopp K, Soler M, Perruchoud AP: Silicone stents in the management of inoperable tracheobronchial stenoses. Indications and limitations. Chest 1993; 104:1653-1659.

$\checkmark 9$ Dutau H, Toutblanc B, Lamb C, Seijo L: Use of the Dumon Y-stent in the management of malignant disease involving the carina: a retrospective review of 86 patients. Chest 2004; 126:951-958.

$\checkmark 10$ Wahidi MM, Unroe MA, Adlakha N, Beyea M, Shofer SL: The use of electrocautery as the primary ablation modality for malignant and benign airway obstruction. J Thorac Oncol 2011;6:1516-1520.

-11 Morice RC, Ece T, Ece F, Keus L: Endobronchial argon plasma coagulation for treatment of hemoptysis and neoplastic airway obstruction. Chest 2001;119:781-787.

12 Schumann C, Hetzel M, Babiak AJ, et al: Endobronchial tumor debulking with a flexible cryoprobe for immediate treatment of malignant stenosis. J Thorac Cardiovasc Surg 2010; 139:997-1000.

\13 Fernandez-Bussy S, Majid A, Caviedes I, Akindipe O, Baz M, Jantz M: Treatment of airway complications following lung transplantation. Arch Bronconeumol 2011;47: 128-133.
14 Sundset A, Lund MB, Hansen G, Bjortuft O, Kongerud J, Geiran OR: Airway complications after lung transplantation: long-term outcome of silicone stenting. Respiration 2012;83:245-252.

15 Dutau H, Cavailles A, Sakr L, et al: A retrospective study of silicone stent placement for management of anastomotic airway complications in lung transplant recipients: shortand long-term outcomes. J Heart Lung Transplant 2010;29:658-664.

16 Anile M, Venuta F, Diso D, et al: Treatment of complex airway lesions after lung transplantation with self-expandable nitinol stents: early experience. Transplant Proc 2010;42: 1279-1280.

17 Fernandez-Bussy S, Akindipe O, Kulkarni V, Swafford W, Baz M, Jantz MA: Clinical experience with a new removable tracheobronchial stent in the management of airway complications after lung transplantation. J Heart Lung Transplant 2009;28:683-688.

18 Neumann K, Sundset A, Espinoza A, Kongerud J, Fosse E: Changes in quality of life, dyspnea scores, and lung function in lung cancer patients with airway obstruction after a therapeutic bronchoscopy. J Bronchology Interv Pulmonol 2013;20:134-139.

19 Amjadi K, Voduc N, Cruysberghs Y, et al: Impact of interventional bronchoscopy on quality of life in malignant airway obstruction. Respiration 2008;76:421-428.

20 Vergnon JM, Costes F, Bayon MC, Emonot A: Efficacy of tracheal and bronchial stent placement on respiratory functional tests. Chest 1995; 107:741-746.

21 Eakin EG, Resnikoff PM, Prewitt LM, Ries AL, Kaplan RM: Validation of a new dyspnea measure: the UCSD Shortness of Breath Questionnaire. University of California, San Diego. Chest 1998;113:619-624.

22 Swigris JJ, Han M, Vij R, et al: The UCSD shortness of breath questionnaire has longitudinal construct validity in idiopathic pulmonary fibrosis. Respir Med 2012;106:14471455.

23 Finlen Copeland CA, Vock DM, Pieper K, Mark DB, Palmer SM: Impact of lung transplantation on recipient quality of life: a serial, prospective, multicenter analysis through the first posttransplant year. Chest 2013;143:744750.
24 Moller A, Sartipy U: Associations between changes in quality of life and survival after lung cancer surgery. J Thorac Oncol 2012;7: 183-187.

25 Swigris JJ, Brown KK, Behr J, et al: The SF-36 and SGRQ: validity and first look at minimum important differences in IPF. Respir Med 2010;104:296-304

26 Ayers ML, Beamis JF Jr: Rigid bronchoscopy in the twenty-first century. Clin Chest Med 2001;22:355-364.

27 Dumon JF: A dedicated tracheobronchial stent. Chest 1990;97:328-332.

28 Celli BR, Cote CG, Marin JM, et al: The bodymass index, airflow obstruction, dyspnea, and exercise capacity index in chronic obstructive pulmonary disease. N Engl J Med 2004;350: 1005-1012.

29 Handa H, Huang J, Murgu SD, et al: Assessment of central airway obstruction using impulse oscillometry before and after interventional bronchoscopy. Respir Care 2014;59: 231-240.

30 Ost DE, Ernst A, Grosu HB, et al: Therapeutic bronchoscopy for malignant central airway obstruction: success rates and impact on dyspnea and quality of life. Chest 2014, Epub ahead of print.

31 Hespanhol V, Magalhaes A, Marques A: Neoplastic severe central airways obstruction, interventional bronchoscopy: a decision-making analysis. J Thorac Cardiovasc Surg 2013; 145:926-932.

- 32 Murthy SC, Blackstone EH, Gildea TR, et al: Impact of anastomotic airway complications after lung transplantation. Ann Thorac Surg 2007;84:401-409, 409.e1-409.e4.

- 33 Van De Wauwer C, Van Raemdonck D, Verleden GM, et al: Risk factors for airway complications within the first year after lung transplantation. Eur J Cardiothorac Surg 2007;31:703-710.

34 Santacruz JF, Mehta AC: Airway complications and management after lung transplantation: ischemia, dehiscence, and stenosis. Proc Am Thorac Soc 2009;6:79-93.

35 Nouraei SA, Mills H, Butler CR, Ghufoor K, Sandhu GS, George PJ: Outcome of treating airway compromise due to bronchial stenosis with intralesional corticosteroids and cutting-balloon bronchoplasty. Otolaryngol Head Neck Surg 2011;145:623-627. 